\title{
Vitamin D deficiency, health and sun exposure: a caveat for the Mediterranean lifestyle
}

\author{
Samir Giuseppe Sukkar
}

Published online: 29 November 2012

(C) Springer-Verlag Italia 2012

\begin{abstract}
Although the use of vitamin D for its skeletal effects, prevention and therapy against osteoporosis is already widely known, in recent years important data have emerged, proving that vitamin $\mathrm{D}$ deficiency correlates an increase in infections risk cardiovascular diseases, autoimmune diseases like multiple sclerosis, type 1 diabetes as well as some malignancies like colorectal and breast cancer.

In a recent meta-analysis, published in the American Journal of Clinical Nutrition, the outcomes of 14 prospective cohort studies were evaluated in more than 62,000 subjects, revealing a connexion between vitamin D-25 $(\mathrm{OH}) \mathrm{D}$ levels and mortality. As a matter of fact, the relative risk of mortality lowers with the increase of $25(\mathrm{OH}) \mathrm{D}$ blood levels and the optimal concentration of this substance has been estimated between 75 and $87.5 \mathrm{nmol} / \mathrm{L}$; beyond this value a further reduction in mortality risk has not been showed. This meta-analysis reveals that there is a statistically non-linear reduction in mortality with respect to $25(\mathrm{OH})$ vitamin D concentrations [1].

This close relationship should probably be associated with the less known extra-skeletal actions of this major calcium regulator hormone.

While vitamin D is indeed one of the most well-known calcium regulatory hormones which helps to maintain the bone trophism, it also has considerable effects on cardiovascular risk, on endocrine-, immune system and infectious-, rheumatologic-, neurodegenerative- and oncological diseases.
\end{abstract}

S. G. Sukkar $(\bowtie)$

U.O. Dietetica e Nutrizione Clinica,

IRCCS Az. Ospedaliera Universitaria San Martino-IST di Genova,

Università di Genova, Pad. VII piano 2,

Largo R. Benzi 10, 16132 Genoa, Italy

e-mail: samir.sukkar@hsanmartino.it
The effects of vitamin D on the nervous system mainly concern the development and maturation of central nervous system neurons. This datum was demonstrated by trials with laboratory animals showing that low levels of circulating vitamin $\mathrm{D}$ are associated with aberrant behavior and inability to learn simple exercises.

It has been observed that vitamin D receptor polymorphisms trigger the onset of neurodegenerative diseases such as Alzheimer's and Parkinson's and people affected by these diseases show reduced vitamin D levels with respect to the general population.

Moreover, trials regarding the administration of $25(\mathrm{OH})$ hydroxyvitamin $\mathrm{D}$ in animals have shown that this therapy protects from neuronal degeneration. Furthermore, animals with vitamin D deficiency, affected by Alzheimer's disease, reported an improvement in their ability to perform physical exercises after administration of non-hydroxylated form of vitamin D (cholecalciferol).

Among the rheumatic diseases vitamin D has a complex role. Vitamin D, thanks to its ability to modulate some functions of the immune system, seems to play a role in the autoimmune diseases since it is able to support the protective mechanisms against rheumatic diseases. As several studies demonstrate, people affected by this kind of disease show low levels of vitamin $\mathrm{D}$, sun exposure is very often contraindicated and, as a consequence, vitamin D supplementation is strongly recommended.

The effect of vitamin D on the cardiovascular system is not yet very well known and further studies are needed to determine if vitamin $\mathrm{D}$ is able to reduce significantly the incidence of cardiovascular events and to establish the optimal level of administration. However, the available data show that good levels of vitamin $\mathrm{D}$, obtained by supplementation, settle a normalization of blood pressure by preventing the development of hypertension with the 
consequent reduction in the incidence of serious cardiovascular events, often fatal, such as myocardial infarction.

Vitamin D is also important to improve the activity of the immune system: HIV-infected patients who run a risk higher than 20-30\% to develop a vitamin D deficiency with respect to the general population, are all recommended to receive daily supplementation of $800 \mathrm{IU}$ of vitamin $\mathrm{D}$, even without having been underwent a prior hypovitaminosis test.

The role played by vitamin D in the onset and manifestation of certain endocrine system disorders, like thyroid diseases, diabetes and some endocrine tumors, is becoming more and more clear, thanks to the new scientific findings. Patients affected by this kind of disorders run a greater risk of having low levels of vitamin D; the dosage of vitamin D and its supplementation, where needed, is therefore necessary.

The vitamin $\mathrm{D}$ can also play a role in the onset of obesity and diabetes. Nowadays, very interesting data are available: vitamin D is one of the factors that can control insulin secretion and some data indicate that good levels of vitamin $\mathrm{D}$ reduce the risk of developing diabetes mellitus and patients with diabetes can be helped to have a better control of this disease [2].

Evidences in animal models have pointed out that the decarboxylated osteocalcin (ucOC), a osteoblasts product, is a hormone which affects pancreas insulin production and insulin sensitivity in peripheral tissues, at least partly by the increased secretion of adiponectin by adipocytes.

The osteocalcin (also known as bone Gla protein, BGP) is a $5 \mathrm{kDa}$ protein and it is the most non-collagen-originated bone protein [3]. It is exclusively synthetized in some cells of the osteoblastic line: mature osteoblasts and osteocytes [4, 5]. Most of the OC are found in bones, but small amounts circulate in the blood and serum levels are considered a bone formation marker [6]. The OC gene transcription is partly regulated by 1,25 -dihydroxyvitamin D levels [7].

The osteocalcin post-translational modification (three gammacarboxylation Gla residues) allows to bind tightly calcium ions in hydroxyapatite (HA) [8-10]. The carboxylation occurs through vitamin K-dependent carboxylase activity, although the mechanism has not been yet fully understood [11]. The decarboxylated OC (ucOC) has less than three carboxylated residues, ranging from none, one or two with, therefore, a lower affinity toward the bone tissue. The completely carboxylated and decarboxylated OC fragments are present both in the bone than in the serum [12]. However, a bigger proportion of ucOC is located in the circulation, while a higher proportion of carboxylated $\mathrm{OC}$ resides in the bone matrix.

$\mathrm{OC}$ is a small secretion protein that is probably able to bind to an unknown receptor on $\beta$ cells, although this has never been proved.
It is of worthwhile interest that the decarboxylated osteocalcin reduces the secretion of insulin and can reduce the glucose plasmatic levels [13, 14]. Physical activity, by stimulating the production of decarboxylated osteocalcin, is assumed to support the insulin-resistance improvement.

It is nowadays estimated that vitamin D deficiency is extremely worldwide spread, especially in the Mediterranean area where, despite the plentiful sun exposure, there is a general vitamin D shortage, even higher than in North Europe countries. In Italy more than $70 \%$ of the population over 75 has a vitamin $\mathrm{D}$ deficiency.

The main source of vitamin $\mathrm{D}$ is formed in humans by the skin exposure to sunlight, which represents $90 \%$ of vitamin D, either in circulating or in deposit form [15-17]. The sunlight, in its UVB component (290-315 nm), is the best and most natural source of Vitamin D obtained by the conversion of 7-dehydrocholesterol into pre-vitamin D3 in human skin. The human body is able to take the necessary amount, by eliminating the excess.

The production of vitamin D after sunlight exposure is also reduced by sun-screen lotions and by melanin production. A SPF 8 sun-screen lotion reduces vitamin D3 skin production of $97.5 \%$ and the increase of the skin melanin pigment has a dramatic effect on the reduction of vitamin D3 skin production [18]. In fact, Afro-American populations show a high incidence of vitamin D deficiency, both in breast-fed infants and in adults [19, 20].

During wintertime, moreover, the sun has a more oblique zenith angle and few B ultraviolet photons can reach the earth's surface. As a result, at a latitude over 35th parallel little or no vitamin D is produced [21, 22].

Aging can also drastically reduce the levels of vitamin D3 precursors (7-dehydrocholesterol) in the skin, dropping by more than four times the production of vitamin D3 in a patient aged 70 years with respect to a 20 -year-old patient [23-25].

However, the skin has a huge capacity to produce vitamin D3. The exposure of the whole body to the sunlight effect can cause a light reddening of the skin (1 minimal erythema dose) equivalent to the intake of 10,000 25,000 IU of vitamin D per os. The exposure of $6 \%$ of the body to 1 minimal erythema dose is equivalent to 600 and 1,000 IU vitamin D intake [26]. Therefore, the exposure to erythema dose of hands, arms, face, or neck two or three times a week is sufficient to satisfy one's vitamin D need [18].

Therefore, it is precisely the lack of sunlight exposure the major factor of the growing increase in vitamin D deficiency. This phenomenon is becoming of universal importance. At the present time, the human beings spend less time in the sun than in any other period of their past history and this is the reason why almost a billion people in the world have vitamin D deficiency. This phenomenon is 
also related to the widespread use of cosmetics and false information about harmful effects of UV light skin exposure. In fact, no study has shown that a regular, moderate sunlight exposure can represent a significant risk for the skin.

The alimentary vitamin supply is, on the other hand, rather poor: in fact, few natural foods contain vitamin $D$ and in limited quantity, just to provide $10 \%$ of the supply only. Food with vitamin D are in fact fatty fish (wild salmon, sardines, mackerel, tuna and cod) and dried mushrooms; lower quantities are found in dairy products and eggs. For this reason, because of the low vitamin D content, food has been enriched with such vitamin. United States and some European countries, by supplementing vitamin D to milk, have in the past contributed to the substantial eradication of rachitism.

Where this practice was not carried out, the administration of cod-liver oil, rich in vitamin $\mathrm{D}$, was the most used system to strengthen the bones in children.

However, starting in the 1950s and 1960s, these customs gradually became less frequent, till they disappeared; as a partial consequence, the incidence of rachitism in children and osteomalacia in adults has significantly raised again.

Vitamin D deficiency is particularly frequent $(>80 \%)$ among the elderly [27-33]. This is related to food shortage, poor inclination to sun exposure with the getting on in years and age-related impairment to vitamin D synthesis. In spite of what often supposed, people over 60 living in the most Southern European regions are the most affected by hypovitaminosis D [34-37]. In the North European countries, the minor incidence is due to several reasons: better "historic" awareness of the problem, major intake of animal fats, fish in particular and frequent supplement of vitamin $\mathrm{D}$ in dairy products. In Italy, a severe vitamin D deficiency (levels of circulating $25 \mathrm{OH}$ vitamin $\mathrm{D}<12$ $\mathrm{ng} / \mathrm{ml}$ ) was found during wintertime in $82 \%$ of subjects aged over 70 [38-40]. The prevalence of deficiency increases in the oldest population, both in women and in men [41, 42], involving practically all the subjects aged $>75$ years.

Even in Islamic countries a major shortage has been recorded.

Muslim women who wear the veil may have low levels of vitamin D. As a result, their children may be at risk of vitamin D deficiency, especially if exclusively breastfed after 6 months of delivery [43-45].

With these considerations, it is important that the scientific community effectively intervenes with a correct communication, by informing people about vitamin deficiency in every age level and facilitating the controlled sun exposure to the sun as an implementation of the Mediterranean lifestyle that, despite a more climatic availability, is characterized by a higher deficiency compared to North Europe population. The scientific community should particularly and strictly act on the populations and ethnic groups who, for religious reasons, bring on a deficit exposure that could lead a significant cancer and metabolism risk in women. In this review, two interesting articles drawn up by Fouda and Skouroliakou underline the scientific community attention toward this issue that should be considered, in the Mediterranean area, as a priority.

\section{References}

1. Zittermann A, Iodice S, Pilz S, Grant WB, Bagnardi V, Gandini S (2012) Vitamin D deficiency and mortality risk in the general population: a meta-analysis of prospective cohort studies. Am J Clin Nutr 95:91-100

2. Motyl KJ, McCabe LR, Schwartzc AV (2010) Bone and glucose metabolism: a two-way street. Arch Biochem Biophys 503(1): $2-10$

3. Lian JB, Gundberg CM (1988) Osteocalcin. Biochemical considerations and clinical applications. ClinOrthop 226:267-291

4. Aarden EM, Wassenaar AM, Alblas MJ, Nijweide PJ (1996) Immunocytochemical demonstration of extracellular matrix proteins in isolated osteocytes. Histochem Cell Biol 106:495-501

5. Ducy P, Desbois C, Boyce B, Pinero G, Story B, Dunstan C, Smith E, Bonadio J, Goldstein S, Gundberg C, Bradley A, Karsenty G (1996) Increased bone formation in osteocalcindeficient mice. Nature 382:448-452

6. Delmas PD, Eastell R, Garnero P, Seibel MJ, Stepan J (2000) The use of biochemical markers of bone turnover in osteoporosis. Committee of Scientific Advisors of the International Osteoporosis Foundation. Osteoporos Int 11:S2-S17

7. Uchida M, Ozono K, Pike JW (1994) Activation of the human osteocalcin gene by 24R,25-dihydroxyvitamin D3 occurs through the vitamin D receptor and the vitamin D-responsive element. J Bone Miner Res 9:1981-1987

8. Hauschka PV, Lian JB, Cole DE, Gundberg CM (1989) Osteocalcin and matrix Gla protein: vitamin $\mathrm{K}$-dependent proteins in bone. Physiol Rev 69:990-1047

9. Hoang QQ, Sicheri F, Howard AJ, Yang DS (2003) Bone recognition mechanism of porcine osteocalcin from crystal structure. Nature 425:977-980

10. Frazao C, Simes DC, Coelho R, Alves D, Williamson MK, Price PA, Cancela ML, Carrondo MA (2005) Structural evidence of a fourth Gla residue in fish osteocalcin: biological implications. Biochemistry 44:1234-1242

11. Rubinacci A (2009) Expanding the functional spectrum of vitamin $\mathrm{K}$ in bone. Focus on: "Vitamin $\mathrm{K}$ promotes mineralization, osteoblast to osteocyte transition, and an anti-catabolic phenotype by \{gamma $\}$-carboxylation-dependent and -independent mechanisms". Am J Physiol Cell Physiol 297:C1336-C1338

12. Cairns JR, Price PA (1994) Direct demonstration that the vitamin $\mathrm{K}$-dependent bone Gla protein is incompletely gamma-carboxylated in humans. J Bone Miner Res 9:1989-1997

13. Tobin BW, Uchakin PN, Leeper-Woodford SK (2002) Insulin secretion and sensitivity in space flight: diabetogenic effects. Nutrition 18:842-848

14. Markin A, Strogonova L, Balashov O, Polyakov V, Tigner T (1998) The dynamics of blood biochemical parameters in cosmonauts during long-term space flights. Acta Astronaut 42:247-253

15. Holick MF (1994) Vitamin D: new horizons for the 21st century. Am J Clin Nutr 60:619-630 
16. Holick MF (1999) Vitamin D: photobiology, metabolism, mechanism of action, and clinical applications. In: Favus MJ (ed) Primer on the metabolic bone diseases and disorders of mineral metabolism, 3rd edn. Lippincott-Raven, Philadelphia, pp 92-98

17. Holick MF (1995) Vitamin D: photobiology, metabolism and clinical applications. In: DeGroot L, Besser M, Burger HG et al (eds) Endocrinology, 3rd edn, chap 59. W.B. Saunders, Philadelphia, pp 990-1013

18. Holick MF (2002) Vitamin D: the underappreciated D-lightful hormone that is important for skeletal and cellular health. Am J Clin Nutr 60:619-630

19. Hartman JJ (2000) Vitamin D deficiency rickets in children: prevalence and need for community education. Orthop Nurs 19:63-68

20. Biser-Rohrbaugh A, Haddley-Miller N (2001) Vitamin D deficiency in breast-fed toddlers. J Pediatr Orthop 21:508-511

21. Webb AR, Kline L, Holick MF (1988) Influence of season and latitude on the cutaneous synthesis of vitamin D3: exposure to winter sunlight in Boston and Edmonton will not promote vitamin D3 synthesis in human skin. J Clin Endocrinol Metab 67:373-378

22. Webb AR, DeCosta BR, Holick MF (1989) Sunlight regulates the cutaneous production of vitamin D3 by causing its photodegradation. J Clin Endocrinol Metab 68:882-887

23. MacLaughlin J, Holick MF (1985) Aging decreases the capacity of human skin to produce vitamin D3. J Clin Invest 76:1536-1538

24. Holick MF, Matsuoka LY, Wortsman J (1989) Age, vitamin D, and solar ultraviolet radiation. Lancet 4:1104-1105

25. Need H, Morris A, Horowitz H et al (1993) Effects of skin thickness, age, body fat, and sunlight on serum 25-hydroxyvitamin D. Am J Clin Nutr 58:882-885

26. Lips P (2000) Vitamin D deficiency and secondary hyperparathyroidism in the elderly: consequences for bone loss and fractures and therapeutic implications. Endocr Rev 22(4):477-501

27. Rossini M, Perbellini S, Lazzarin M, Adami S, Bertoldo F, Lo Cascio V (1990) Incidenza di ipovitaminosi D nel Nord Italia. It J Min Elect Metab 4(1):13-17

28. van der Wielen RPJ, Lowik MRH, van den Berg H, de Groot LCPGM, Haller J, Moreiras O, van Staveren WA (1995) Serum vitamin D concentrations among elderly people in Europe. Lancet 346:207-210

29. Bettica P, Bevilacqua M, Vago T, Norbiato G (1999) High prevalence of hypovitaminosis D among free-living postmenopausal women referred to an osteoporosis outpatient clinic in northern Italy for initial screening. Osteoporos Int 9(3):226-229

30. Lips P, Duong T, Oleksik A, Black D, Cummings S, Cox D, Nickelsen T (2001) A global study of vitamin D status and parathyroid function in postmenopausal women with osteoporosis: baseline data from the multiple outcomes of raloxifene evaluation clinical trial. J Clin Endocrinol Metab 86:1212-1221
31. Isaia G, Giorgino R, Rini GB, Bevilacqua M, Maugeri D, Adami S (2003) Prevalence of hypovitaminosis D in elderly women in Italy: clinical consequences and risk factors. Osteoporos Int 14:577-582

32. Kuchuk NO et al (2009) Vitamin D status, parathyroid function, bone turnover, and BMD in postmenopausal women with osteoporosis: global perspective. J Bone Miner Res 24:693-701

33. Mithal A et al (2009) Global vitamin D status and determinants of hypovitaminosis D. Osteoporos Int 20:1807-1820

34. Wielen van der RPJ, Lowik MRH, Berg van den $\mathrm{H}$, Groot de LCPGM, Haller J, Moreiras O, Staveren van WA (1995) Serum vitamin D concentrations among elderly people in Europe. Lancet 346: 207-210

35. Lips P, Duong T, Oleksik A, Black D, Cummings S, Cox D, Nickelsen T (2001) A global study of vitamin D status and parathyroid function in postmenopausal women with osteoporosis: baseline data from the Multiple Outcomes of Raloxifene Evaluation clinical trial. J Clin Endocrinol Metab 86:1212-1221

36. Kuchuk NO et al (2009) Vitamin D status, parathyroid function, bone turnover, and BMD in postmenopausal women with osteoporosis: global perspective. J Bone Miner Res 24:693-701

37. Mithal A et al (2009) Global vitamin D status and determinants of Hypovitaminosis D. Osteoporos Int 20:1807-1820

38. Rossini M, Perbellini S, Lazzarin M, Adami S, Bertoldo F, Lo Cascio V (1990) Incidenza di ipovitaminosi D nel Nord Italia. It J Min Elect Metab 4(1):13-17

39. Bettica P, Bevilacqua M, Vago T, Norbiato G (1999) High prevalence of hypovitaminosis D among free-living postmenopausal women referred to an osteoporosis outpatient clinic in northern Italy for initial screening. Osteoporos Int 9(3):226-229

40. Isaia $\mathrm{G}$, Giorgino R, Rini GB, Bevilacqua M, Maugeri D, Adami S (2003) Prevalence of hypovitaminosis D in elderly women in Italy: clinical consequences and risk factors. Osteoporos Int 14:577-582

41. Maggio D et al (2005) 25(OH)D serum levels decline with age earlier in women than in men and less efficiently prevent compensatory hyperparathyroidism in older adults. J Gerontol A Biol Sci Med Sci 60:1414-1419

42. Orwoll E et al (2009) Vitamin D deficiency in older men. J Clin Endocrinol Metab 94:1214-1222

43. Seeler RA (2001) Religious/cultural causes of vitamin D deficiency in infants. J Pediatr 138:954

44. Guzel R, Kozanoglu E, Guler-Uysal F et al (2001) Vitamin D status and bone mineral density of veiled and unveiled Turkish women. J Womens Health Gend Based Med 10:765-770

45. Bachrach S, Fisher J, Parks JS (1979) An outbreak of vitamin D deficiency rickets in a susceptible population. Pediatrics 64:871-877 